University of Nebraska - Lincoln

DigitalCommons@University of Nebraska - Lincoln

USDA Wildlife Services - Staff Publications

U.S. Department of Agriculture: Animal and Plant Health Inspection Service

2021

\title{
Daily and Landscape Influences of Species Visitation to Toxic Bait Sites for Wild Pigs
}

\author{
Nathan P. Snow \\ USDA APHIS Wildlife Services, nathan.p.snow@aphis.usda.gov \\ Joseph M. Halseth \\ USDA/APHIS/ Wildlife Services, National Wildlife Research Center \\ Michael P. Glow \\ USDA National Wildlife Research Center \\ Michael Lavelle \\ USDA, Animal and Plant Health Inspection Service, michael.j.lavelle@aphis.usda.gov \\ Justin Fischer \\ USDA-APHIS-Wildlife Services, Justin.w.fischer@aphis.usda.gov \\ Follow this and additional works at: https://digitalcommons.unl.edu/icwdm_usdanwrc

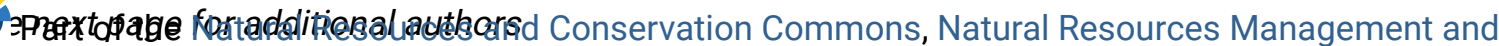 \\ Policy Commons, Other Environmental Sciences Commons, Other Veterinary Medicine Commons, \\ Population Biology Commons, Terrestrial and Aquatic Ecology Commons, Veterinary Infectious Diseases \\ Commons, Veterinary Microbiology and Immunobiology Commons, Veterinary Preventive Medicine, \\ Epidemiology, and Public Health Commons, and the Zoology Commons
}

Snow, Nathan P.; Halseth, Joseph M.; Glow, Michael P.; Lavelle, Michael; Fischer, Justin; VanNatta, Eric H.; and Vercauteren, Kurt C., "Daily and Landscape Influences of Species Visitation to Toxic Bait Sites for Wild Pigs" (2021). USDA Wildlife Services - Staff Publications. 2441.

https://digitalcommons.unl.edu/icwdm_usdanwrc/2441

This Article is brought to you for free and open access by the U.S. Department of Agriculture: Animal and Plant Health Inspection Service at DigitalCommons@University of Nebraska - Lincoln. It has been accepted for inclusion in USDA Wildlife Services - Staff Publications by an authorized administrator of DigitalCommons@University of Nebraska - Lincoln. 


\section{Authors}

Nathan P. Snow, Joseph M. Halseth, Michael P. Glow, Michael Lavelle, Justin Fischer, Eric H. VanNatta, and Kurt C. Vercauteren 


\title{
Daily and Landscape Influences of Species Visitation to Toxic Bait Sites for Wild Pigs
}

\author{
NATHAN P. SNOW (D), ${ }^{1}$ USDA/APHIS/Wildife Services, National Wildlife Research Center, 4101 LaPorte Ave., Fort Collins, CO 80521, USA \\ JOSEPH M. HALSETH, USDA/APHIS/Wildlife Services, National Wildlife Research Center, 4101 LaPorte Ave., Fort Collins, CO 80521, USA \\ MICHAEL P. GLOW, USDA/APHIS/Wildlife Services, National Wildlife Research Center, 4101 LaPorte Ave., Fort Collins, CO 80521, USA \\ MICHAEL J. LAVELLE D, USDA/APHIS/Wildife Services, National Wildlife Research Center, 4101 LaPorte Ave., Fort Collins, CO 80521, USA \\ JUSTIN W. FISCHER, USDA/APHIS/Wildlife Services, National Wildlife Research Center, 4101 LaPorte Ave., Fort Collins, CO 80521, USA \\ ERIC H. VANNATTA, USDA/APHIS/Wildlife Services, National Wildlife Research Center, 4101 LaPorte Ave., Fort Collins, CO 80521, USA \\ KURT C. VERCAUTEREN, USDA/APHIS/Wildlife Services, National Wildife Research Center, 4101 LaPorte Ave., Fort Collins, CO 80521, USA
}

\begin{abstract}
Toxic baiting of wild pigs (Sus scrofa) is a potential new tool for population control and damage reduction in the United States. Use of toxic bait sites by non-target species is concerning because of the risks posed from exposure to a toxic bait. A 2018 field trial in northern Texas, USA, examining the efficacy of a prototype toxic bait (HOGGONE ${ }^{\circledR}$, containing $10 \%$ sodium nitrite) revealed unexpected hazards to non-target species, primarily passerine birds, from consuming toxic bait spilled outside of bait stations by wild pigs. The hazards jeopardize the ability to register HOGGONE as a tool for controlling wild pigs. We conducted a post hoc analysis from that 2018 trial to identify how daily and landscape factors influenced the use of bait sites by non-target species, and subsequent hazards from consuming the toxic bait. We discovered that no single strategy can eliminate visitations by all non-target species, but offering the toxic bait at night, in wild-pig specific bait stations, and in more homogeneous landscapes appeared to be the best strategy for minimizing visits by passerine birds. We also found that use of bait sites by wild pigs were temporally clustered, and more pigs visited bait sites along linear features of the landscape (e.g., agricultural edges or riparian corridors). We recommend a baiting strategy where applicators do not place bait stations directly at sites where remnant particles of grain (from prebaiting) are available on the ground. Published 2021. This article is a U.S. Government work and is in the public domain in the USA.
\end{abstract}

KEY WORDS anthropogenic feeding, baiting, behavior, hunting, Sus scrofa, toxicant, trapping, wild boar, wildlife damage management.

Wild pigs (Sus scrofa), also termed feral hogs, feral pigs, feral swine, invasive wild pigs, or wild boar (Keiter et al. 2016), are a destructive invasive species that have been introduced throughout much of the world (Seward et al. 2004, Bevins et al. 2014). Wild pigs are sources for zoonotic and livestock diseases, cause extensive damage to agricultural crops, private property, and natural resources, and threaten imperiled species (Seward et al. 2004, Pimentel et al. 2005, Barrios-Garcia and Ballari 2012, Bevins et al. 2014, McClure et al. 2018). Populations of wild pigs have been expanding their range in the United States (McClure et al. 2015, Snow et al. 2017b, Tabak et al. 2017), Canada (Brook and van Beest 2014, Aschim and Brook 2019), and Australia (Bengsen et al. 2014), and have potential to continue increasing in density throughout these regions

Received: 22 August 2019; Accepted: 19 August 2020

Published: 26 February 2021

${ }^{1}$ E-mail: Nathan.P.Snow@usda.gov
(Lewis et al. 2017). New methods to curtail the expansion of wild pigs, such as orally-delivered toxic baits, are under development in multiple countries, (Shapiro et al. 2016, Snow et al. 2017a, Poché et al. 2018), but risks to nontarget species remain a concern (Koichi et al. 2013, DeGroot 2018, Lavelle et al. 2018a, Snow et al. 2018, TuckerWilliams 2018).

Baits designed to attract wild pigs are usually also attractive to non-target wildlife, such as white-tailed deer (Odocoileus virginianus), raccoons (Procyon lotor), birds, and other species (e.g., Campbell and Long 2007, 2008; Snow et al. 2016; Lavelle et al. 2017). Baiting for wild pigs without attracting non-target species would be most successful when non-target populations are low during their annual population cycle or have migrated elsewhere, and when availability of preferred foods are at a minimum (Sweetapple et al. 2002, Howald et al. 2007, Lavelle et al. 2017). Meeting these prerequisites is challenging for baiting of wild pigs given their vast distribution and overlap with non-target species, and their ability to exploit numerous 
food resources (Mayer and Brisbin 2009). When the prerequisites are not met, non-target species are known to consume bait meant for wild pigs (Fletcher et al. 1990, Campbell and Long 2007, Snow et al. 2016), and reduce the effectiveness of control activities (e.g., by indavertently triggering traps; Campbell and Long 2009). Finally, the presence of non-target species during baiting for population control of wild pigs using toxic baits increases the probabilities of non-target mortalities from consumption of the bait (Campbell et al. 2011, Lapidge et al. 2012, Snow et al. 2017c, Lavelle et al. 2018a).

The recent development of three new toxic baits for wild pigs in the US, Australia, and New Zealand (Kaput ${ }^{\circledR}$ Scimetrics Ltd. Corp, Wellington, CO, USA; HOGGONE $^{\circledR}$, Animal Control Technologies [Australia] Pty Ltd, Somerton, VIC, AU; and BAIT-RITE PASTE ${ }^{\circledR}$, Connovation, East Tamaki, Auckland, NZ) emphasizes the need to identify baiting strategies that minimize the presence of non-target animals and maximize numbers of wild pigs at bait sites. In order to exclude non-target species from directly accessing a toxic bait, wild pig-specific bait stations have been developed and used in the field (Shapiro et al. 2016, Snow et al. 2017c, Lavelle et al. 2018a, Poché et al. 2018). Using bait stations requires an $~ 2-3$ week training period for wild pigs to learn how to access the bait station (Long et al. 2010, Campbell et al. 2013, Lavelle et al. 2018b, Poché et al. 2018). During the initial phases of locating wild pigs and training them to use the bait station, nontoxic bait is initially placed on the ground for several days before transitioning to the bait station, which is then left open or partially open. Thus, non-target animals can access the bait and become accustomed to supplemental food. Once a bait station is locked closed against non-target species, wild pigs may spill small amounts of bait outside of the bait stations (Massei et al. 2010, Campbell et al. 2011, Ferretti et al. 2018), which puts non-target animals at risk of consuming toxic bait.

A recent field trial with the prototype HOGGONE toxic bait, containing 10\% sodium nitrite, during March 2018 in northern Texas revealed the issues associated with nontarget species accessing toxic bait spilled by wild pigs. Although the experimental trial resulted in reducing the population of wild pigs by $70 \%$ in 1-2 nights of toxic baiting at 14 bait sites, it also resulted in 171 bird mortalities (primarily white-crowned sparrows [Zonotrichia leucophrys] and red-winged black birds [Agelaius phoeniceus]) and 8 raccoon mortalities from consuming HOGGONE spilled outside of the bait stations by wild pigs (United States Department of Agriculture 2018). The unexpected hazards jeopardized the ability to register HOGGONE as a new tool for controlling wild pigs in the US. As such, the developers of HOGGONE are attempting to mitigate the hazards by, 1) a reformulation of the prototype HOGGONE bait to be more palatable to free-ranging wild pigs, 2) a revised bait delivery system to minimize spillage by wild pigs, and 3) a shortened prebaiting and conditioning strategy to minimize the training of non-target species to use bait sites. Despite the changes, we wanted to evaluate data from the 2018 HOGGONE trial to examine for any attributes from daily baiting procedures or surrounding landscape that could inform strategies for reducing non-target animals at bait sites.

The US Environmental Protection Agency limits the use of unregistered pesticides such as HOGGONE to reduce environmental risks. In an effort to gain as much information as possible from the 2018 HOGGONE trial, we conducted this study post hoc to learn from the unexpected hazards. To our knowledge, no studies have examined factors that influence visitation by wild pigs and non-target species to toxic bait sites to provide insight on reducing risks to non-targets. Our objectives were as follows: 1) determine whether any conditions associated to daily timing or strategy of baiting influenced the frequency of non-target visits to bait sites, 2) determine whether any characteristics of the landscape surrounding bait sites influenced the amount of non-target visits to bait sites, and 3) determine whether the numbers of wild pigs or non-target species visiting the bait sites influenced the number of non-target mortalities observed. Our goals were to provide guidance for reducing exposure of nontargets to toxic bait sites for wild pigs, while maximizing exposure of wild pigs to toxic bait for the purposes of population control.

\section{STUDY AREA}

The study was conducted on a section of private land encompassing approximately $52 \mathrm{~km}^{2}$ in Wilbarger County, Texas, USA, from January-March 2018 (Fig. 1). The study area lies within the Southwest Plateau and Plains Dry Steppe and Shrub ecoregion of North America (Bailey 1980), and the Rolling Plains ecoregion of Texas. Topography was characterized by flat to rolling plains and plateaus with scattered drainages and canyons at an elevation of approximately $350 \mathrm{~m}$ above sea level. Land use practices primarily included cattle grazing operations and crude oil development and extraction. Vegetation was primarily comprised of mesquite (Prosopis spp.), oak (Quercus spp.), hackberry (Celtis occidentalis), cottonwood (Populus deltoides), chinaberry (Melia azedarach), prickly pear (Opuntia spp.), and a variety of grass species including grama (Bouteloua spp.) and bluegrass (Poa spp.). The climate was classified as semiarid, experiencing long, hot, and dry summers with short, mild winters. Temperatures during our study ranged from $-13-33^{\circ} \mathrm{C}$, and daily precipitation averaged $0.7 \mathrm{~mm}$.

\section{METHODS}

\section{Baiting Wild Pigs}

We selected bait sites by overlaying the study area with a $0.75 \times 0.75 \mathrm{~km}$ grid (based on Kay et al. 2017, Lavelle et al. 2018b, Snow et al. 2019, Snow and VerCauteren 2019), and focusing on grid cells that had fresh sign of wild pigs (e.g., feces, tracks, rooting, wallows). This grid size allowed us to expose an estimated $90-100 \%$ of wild pigs to bait in the study area (Snow and VerCauteren 2019). 


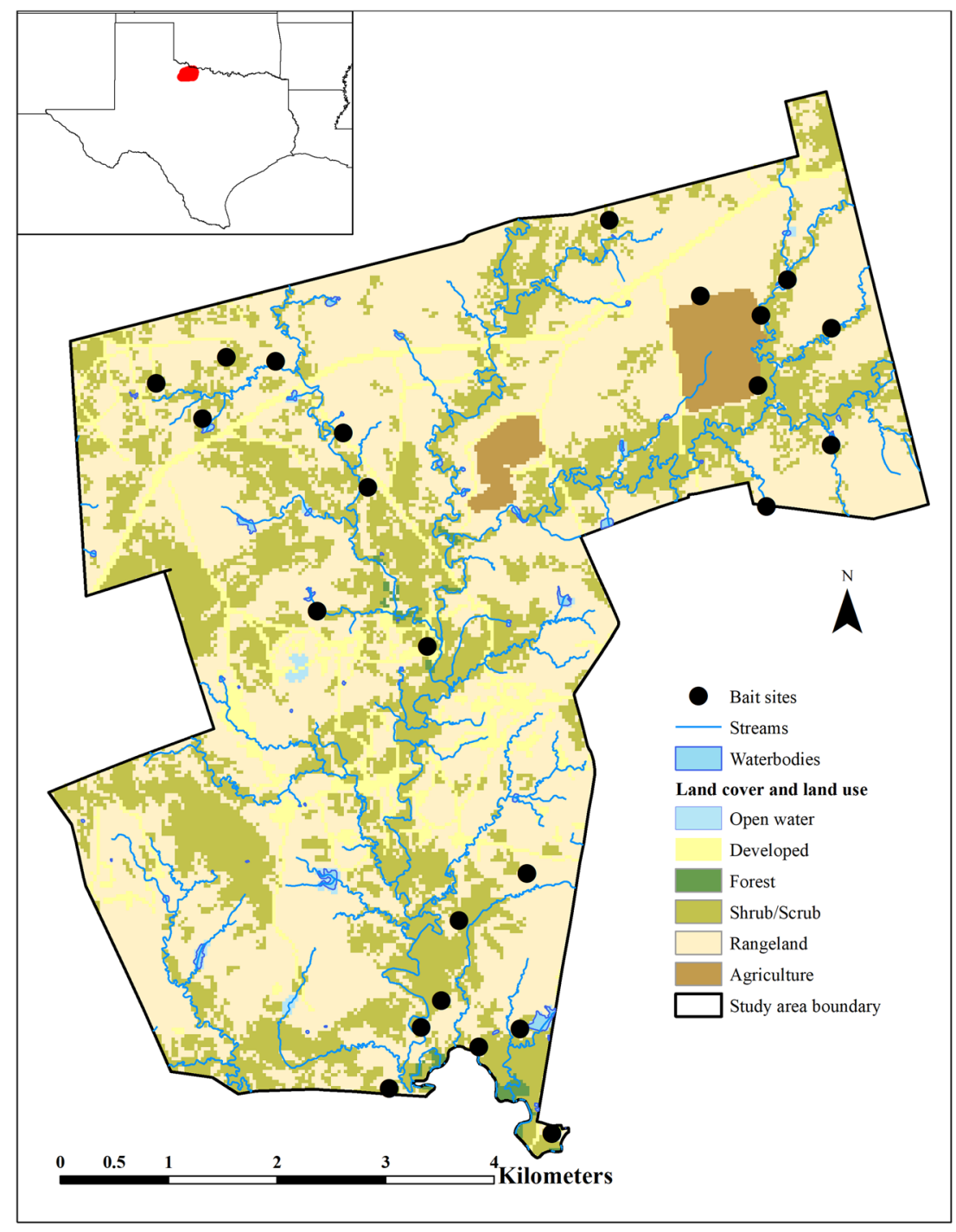

Figure 1. Study area and bait sites in north-central Texas, USA, for examining the visitation rates of non-target species to bait sites for wild pigs, January-March 2018.

Within the selected cells, we established 1-3 bait sites by deploying $11.3 \mathrm{~kg}$ of whole-kernel corn in locations near fresh sign. We monitored sites with remote cameras (RECONYX PC900, RECONYX, Inc., Holmen, WI, USA), conducted daily checks, and added bait as needed. After baiting sites for 2-6 days, we then chose the best site within each grid cell and ceased baiting the remaining sites. We chose the best sites using the greatest ranking strategy developed by Snow et al. (2019): 1) consistent wild pig visitation (i.e., $\geq 2$ days in a row), 2) consistent visitation by a sounder of wild pigs (i.e., $\geq 1$ female with piglets), 3) consistent visitation by $>1$ sounder, and 4) consistent visitation by a sounder(s) that was independent from those visiting nearby bait sites. Overall, we initiated baiting with 41 sites and narrowed these down to the 24 best sites at baiting density of $\leq 1$ bait site $/ 0.75 \mathrm{~km}^{2}$. We constructed three-strand barbed wire exclosures (bottom strand with smooth wire) around any baiting site where cattle were present and could access the bait sites.
After selecting the greatest ranking bait sites, we began deploying 1-2 wild pig-specific bait stations at each site. To ensure enough bait capacity for feeding all wild pigs that visited our sites, we deployed 1 bait station for sites with $\leq 10$ wild pigs, and two bait stations for sites with $>10$ wild pigs. Each bait station $(137 \times 36 \times 17 \mathrm{~cm})$ was constructed of 2 back-to-back troughs with overhanging lids capable of being propped open at varying heights or secured shut with $13 \mathrm{~kg}$ of magnetic resistance (Snow et al. 2017d; Lavelle et al. 2018a, $b$; Snow et al. 2019). Bait stations were secured to the ground by wiring the handles on either side of the bait station to a steel T-post. We acclimated wild pigs to use the bait stations and to consume placebo HOGGONE bait by employing a wild pig-informed baiting strategy with deliberate stages (Table 1), where we progressively advanced through each stage once wild pigs accessed and consumed bait for two consecutive nights at the previous stage (Lavelle et al. 2018b, Snow et al. 2019). After all acclimation stages we deployed toxic HOGGONE 
Table 1. Baiting strategy used for locating, acclimating wild pigs to a wild pig-specific bait station, and consuming HOGGONE ${ }^{\circledR}$ bait in north-central Texas, USA, January-March 2018.

\begin{tabular}{|c|c|c|c|c|}
\hline \multirow[b]{2}{*}{ Baiting stage } & \multirow[b]{2}{*}{ No. days at stage ${ }^{a}$} & \multicolumn{3}{|c|}{ Bait deployed at each site daily (kg) } \\
\hline & & Whole-kernel corn & Placebo HOGGONE & Toxic HOGGONE \\
\hline Pre-baiting-locate wild pigs & $2-6$ & 11.3 & & \\
\hline Introduce placebo HOGGONE & 2 & 11.3 & 0.25 & \\
\hline Introduce bait stations, lids propped to $25 \mathrm{~cm}$ & 2 & 11.3 & 0.5 & \\
\hline Bait station lids propped to $5 \mathrm{~cm}$ & 2 & 7.7 & 5.5 & \\
\hline Bait station lids closed, $0 \mathrm{~kg}$ magnetic resistance & 2 & 5.5 & 10.0 & \\
\hline Bait station lids closed, $13 \mathrm{~kg}$ magnetic resistance & 2 & 0.5 & 20.0 & \\
\hline Bait station lids closed, $13 \mathrm{~kg}$ magnetic resistance & 2 & 0.5 & & 20.0 \\
\hline Bait station lids closed, $13 \mathrm{~kg}$ magnetic resistance & 2 & & 20.0 & \\
\hline
\end{tabular}

${ }^{a}$ Represents an approximate number of days operated at each stage. Baiting stages were progressed based on a pig-informed strategy (Lavelle et al. 2018b), where two days of consistent visitation and consumption of bait by wild pigs was required before proceeding to the next stage.

bait for two nights, followed by two nights of placebo HOGGONE, in order to evaluate how many wild pigs survived the toxic baiting.

\section{Quantifying Visits to Bait Sites}

We monitored all bait sites with remote cameras mounted on steel T-posts or trees $5 \mathrm{~m}$ away from the bait sites and $1.5 \mathrm{~m}$ above ground. We programmed cameras to record time-lapse imagery at a rate of one image every five minutes for a total of 288 images in a 24 -hour period. We processed all camera images using the Colorado Parks and Wildlife Photo Warehouse Database (Ivan and Newkirk 2016). In each image we recorded date, time, and the count of each species present. We aggregated these data into 30-minute intervals (i.e., 6 consecutive images) based on the average duration of feeding bouts observed at bait sites in previous studies (Snow et al. 2016). Within each interval, we identified the maximum count of each species from a single image. We used the maximum count as a conservative measure of the number of each species present during each 30-minute interval.

We classified all non-target species observed at the bait sites into four categories: passerine birds, ground birds, raccoons, and white-tailed deer. Passerine birds were composed primarily of white-crowned sparrows, house sparrows (Passer domesticus), dark-eyed juncos (Junco hyemalis), red-winged blackbirds, brown-headed cowbirds (Molothrus ater), northern cardinals (Cardinalis cardinalis), meadowlarks (Sturnella spp.), American crows (Corvus brachyrhynchos), and small proportions of other species that could not be identified in images. We included doves (Zenaida spp.) with the passerine birds because they commonly use perches like many passerines. Ground birds consisted of bobwhite quail (Colinus virginianus) and wild turkeys (Meleagris gallopavo).

\section{Daily Predictors of Bait Site Usage}

We examined how four predictors influenced the frequency of visitations by non-target species and wild pigs on a daily basis (Table 2). First, we classified all visits into time-of-day categories including dawn, dusk, day, and night visits. Dawn visits were considered as 1 hour before to 1 hour after sunrise Dusk visits were considered as 1 hour before to 1 hour after sunset. Day visits occurred between dawn and dusk, and night visits occurred between dusk and dawn. Second, we classified all visits into categories based on the

Table 2. Explanatory variables and predictions evaluated for influences on the visitation rates of non-target species and wild pigs to bait sites in north-central Texas, USA, January-March 2018.

\begin{tabular}{|c|c|}
\hline Predictors & Biological prediction \\
\hline \multicolumn{2}{|l|}{ DAILY ANALYSIS } \\
\hline Time-of-day & More animals visit bait sites during crepuscular hours \\
\hline Stage of bait station & Fewer animals visit when bait station is closed \\
\hline Days of baiting & More animals visit the longer baiting occurs \\
\hline Time since wild pig & More animals visit sooner after wild pigs visit \\
\hline \multicolumn{2}{|l|}{ LANDSCAPE ANALYSIS } \\
\hline \multicolumn{2}{|l|}{ Composition } \\
\hline Proportion of agriculture & More animals visit in landscapes with more agriculture \\
\hline Proportion of forest & More animals visit in landscapes with more forest \\
\hline \multicolumn{2}{|l|}{ Configuration } \\
\hline Edge density & More animals visit in landscapes with more edges \\
\hline Contagion & More animals visit in landscapes that are less contiguous \\
\hline \multicolumn{2}{|r|}{ the } \\
\hline Stream & More animals visit near streams \\
\hline Waterbody & More animals visit near water bodies \\
\hline
\end{tabular}


stage of the bait station at each bait site, no bait station placed (i.e., bait on the ground), lid propped open (i.e., initially propped open $25 \mathrm{~cm}$, and then reduced to $5 \mathrm{~cm}$ to facilitate training of wild pigs), and lid fully closed (i.e., initially closed without magnetic resistance, and then with $\sim 13 \mathrm{~kg}$ of magnetic resistance added to facilitate training of wild pigs and exclude non-targets). Third, we calculated the number of baiting days for each visit as the count of days since a bait site was initiated (i.e., bait first placed). Fourth, we calculated the time (hours) since the last visit to the bait site by a wild pig.

\section{Landscape Predictors of Bait Site Usage}

We examined how the landscape surrounding bait sites influenced the frequency of non-target and wild pig visits by quantifying metrics of composition, configuration, and distances (Table 2). For the metrics of composition and configuration, we examined buffers around the bait sites of 100,500 , and $1,000 \mathrm{~m}$, representing local, moderate, and broad scales, respectively. We used ArcGIS (version 10.5.1; Environmental Systems Research Institute, Redlands, CA, USA) to reclassify the 2011 National Land Cover Database (Jin et al. 2013) from 13 to 6 classes: rangeland (59\%), shrubland $(31 \%)$, developed $(7 \%)$, agriculture $(3 \%)$, water $(1 \%)$, and forest $(<1 \%)$ We considered these classes to represent important land cover and land use classes for wild pigs and non-target species within the study area. We then used program FRAGSTATS (version 4.1, University of Massachusetts, Amherst, MA, USA) to calculate metrics of landscape composition and configuration.

For composition, we calculated the proportion of agriculture, rangeland, and forest surrounding the bait sites at each spatial scale. For configuration, we calculated the edge density between cover types, as the sum of the length of borders between cover types divided by the area of the buffer used around the bait sites $\left(\mathrm{m} / \mathrm{m}^{2}\right)$. We also calculated contagion as an index of the spatial aggregation and interspersion of similar patch types at each spatial scale ( $\mathrm{Li}$ and Reynolds 1993). A contagion value of 0 represented a greatly fragmented and intermixed landscape, whereas a value of 100 represented a landscape comprised of a single patch type. Finally, we used the United States Geological Survey, National Hydrology Dataset and the NEAR tool in ArcGIS to calculate the distances (m) from each bait site to the nearest stream and water body (i.e., cattle tank or pond). We also calculated the distance $(\mathrm{m})$ from each bait site to the nearest neighboring bait site.

\section{Predictors of Mortality at Bait Sites}

The morning following toxic bait deployment, we walked systematic transects $(600 \times 600 \mathrm{~m}$, every $40 \mathrm{~m})$ around the bait sites to record the location and species of any carcasses observed. We paired the counts of carcasses with the counts of each species observed at each bait site on remote cameras prior to the deployment of the toxic bait. Specifically, we averaged the counts of each species observed/hour during the $2-3$ days preceding toxic bait deployment (i.e., lid fully closed on the bait station) to make sure the usage of the bait site and subsequent mortalities from the toxic baiting were temporally aligned.

\section{Data Analysis}

The framework for data analysis in this study was an exploratory examination for those variables influencing nontarget species and wild pig use of bait sites the most. We repeated all analyses for each species category (i.e., passerine birds, ground birds, raccoons, white-tailed deer, and wild pigs). We conducted an intercorrelation analysis of the daily and landscape predictors, respectively, and identified no correlated pairs of predictors (i.e., $|\mathrm{r}| \geq 0.60$ ) using program R (v3.6.3; R Core Team 2020).

For the daily analysis of bait site usage, we used zeroinflated negative binomial mixed regression models from the glmmTMB package in $\mathrm{R}$ (Brooks et al. 2017) to evaluate which daily predictors influenced the maximum count of each species during the 30 minute intervals. Specifically, we evaluated the model Count $\sim$ Time of day + Stage of bait station + Days since site initiated + Hour since last wild pig. We applied a single zero-inflation parameter to all observations. We treated the bait site ID as a random effect to account for repeated measures taken at each bait site. We evaluated this model separately for passerine birds, ground birds, non-target mammals, and wild pigs, respectively. For all models, we examined the 95\% confidence intervals (CIs) for the regression coefficients for overlap of zero to ascertain which covariates had clear effects on the count of species (Burnham and Anderson 2002). Finally, we used 5,000 iterations of bootstrap sampling to construct predictive plots and $95 \%$ CIs around the predictions to examine the predicted relationships for each species.

For the landscape analysis of bait site usage, we summed the counts of visitations observed during each 30 minute interval for each species at each bait site each day. Then we averaged the sums among the first five days bait was offered on the ground for each bait site. We only used the first five days because this allowed us to avoid confounding visitations with the presence of the bait station that was designed to exclude non-target species. Also, we combined the visits from ground birds, raccoons, and white-tailed deer into an overall group of terrestrial non-targets to alleviate issues from small sample sizes for each of the species independently. Therefore, we analyzed how features of the landscape influenced visitations by passerine birds, terrestrial non-targets, and wild pigs, respectively.

We estimated the effects of landscape predictors on the count of visitations by each groups of species using negative binomial generalized linear modeling in R. We employed a model selection procedure, similar to Danks and Porter (2010), to identify the most parsimonious models that best described the relationships between the landscape and bait site visitation for each group of species. Specifically, we tested a priori models within each of three landscape component categories: landscape composition, landscape configuration, and distances to feature (Table 2). Within the landscape composition and configuration categories we 
examined models for each buffer size. We used Akaike's Information Criterion corrected for small sample sizes (AICc) to rank the candidate models within each landscape category, with the MuMIn package in R (Barton 2009). We used the predictors contained in the top model for each category to develop an overall full (global) model for that species or group of species. We then derived a reduced model by screening for noncontributing predictors within the full model, by removing each predictor from the full model in turn, and examining the change in AICc. We only retained the predictors that reduced the AICc by $>2.0$ (Burnham and Anderson 2002) when retained, representing a reduced model of only important predictors for each species group. We used the reduced model to construct predictive plots and make inferences about which predictors had influences on the visitation for each group of species to bait sites.

For the predictors of mortalities at bait sites, we evaluated whether the amount of visitation at bait sites by each category of species influenced the number of mortalities found for those species, respectively, following the deployment of toxic HOGGONE. Specifically, we used Poisson generalized linear models with log-links in $\mathrm{R}$ to evaluate the relationships between visitation and mortalities for passerine birds, ground birds, non-target mammals, and wild pigs, respectively. We constructed predictive plots with 95\% confidence intervals $(\mathrm{CIs})$ to evaluate the strength of the relationships.

\section{RESULTS}

Overall, we observed an average of 6.5 passerine birds, 6.0 wild pigs, 1.2 ground birds, 0.2 raccoons, and 0.02 whitetailed deer/day among the 24 bait sites. Frequent visits by passerine birds were observed and sustained after the first
3 days that baiting was implemented (Fig. 2), with the exception of days 9-12 when heavy rain and snow occurred. Counts of ground birds and raccoons were lower and mostly consistent across the baiting period. White-tailed deer did not use the bait sites often, and not at all after the first week of baiting. Counts of wild pigs remained steady between days 3-20, indicating the training stages with the bait station were adequate for maintaining their attractiveness to wild pigs while training them to use a bait station. Visitation by wild pigs declined only after the toxic HOGGONE was deployed ( day 20), and systematic carcass searches indicated that $\geq 109$ wild pigs were removed from 14 of the bait sites.

We found that passerine bird visits were greatest during the dawn hours, and decreased throughout the day and night (Table 3; Fig. 3A). Using the bait stations with the lids open or closed reduced visits by passerine birds (Fig. 3B). However, visitation by passerines increased the longer that bait sites were operated (Fig. 3C), and did not seem to be influenced by the timing of visitations by wild pigs (Fig. 3D). Ground birds had the greatest visitation during the daytime hours, and their use of bait sites was greatest during the prebaiting stage. Ground birds were not influenced by the duration the bait site was operated or the timing of wild pig visitation. Non-target mammals included raccoons only, because white-tailed deer ceased using bait sites early in the prebaiting process. Raccoon visits were greatest at night, and when the bait station was deployed (lids open or closed). Raccoon visitation declined the longer that bait sites were operated, and raccoons had increased visitation the longer that wild pigs were away from the bait sites. Finally, wild pigs visited bait sites the most during dusk and least during dawn hours. Visitation by wild pigs increased when the bait station was deployed (lids open or

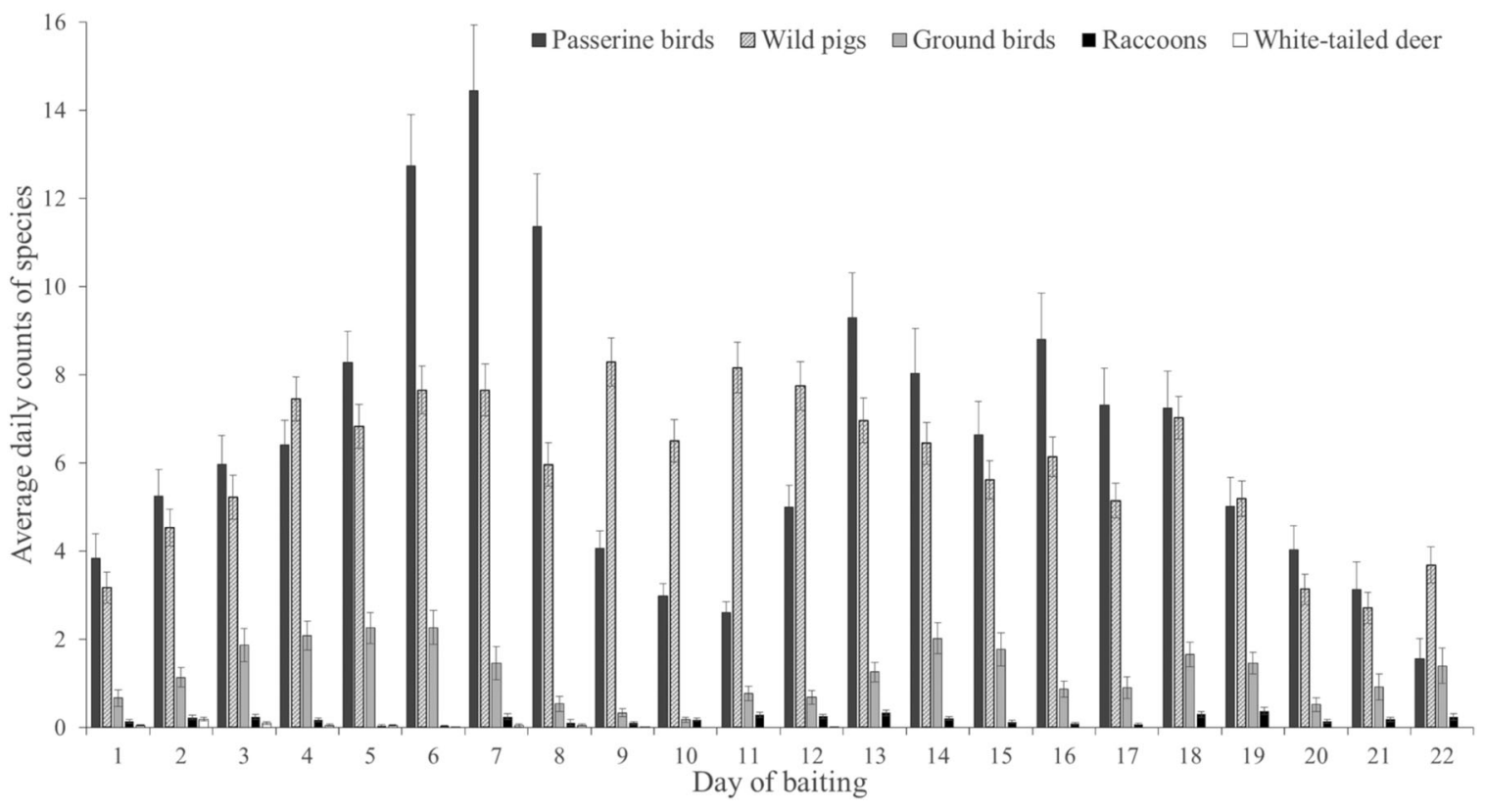

Figure 2. Average daily total count of species visiting bait sites for wild pigs observed in north-central Texas, USA, January-March 2018. 
Table 3. Parameter estimates ( $\beta$ ), $95 \%$ lower confidence limits (LCL), and $95 \%$ upper confidence limits (UCL) examining the daily influences on visitation rates of non-target species to bait sites for wild pigs in northcentral Texas, USA, January-March 2018.

\begin{tabular}{|c|c|c|c|c|c|c|c|c|c|c|c|c|}
\hline & \multicolumn{3}{|c|}{ Passerine birds } & \multicolumn{3}{|c|}{ Ground birds } & \multicolumn{3}{|c|}{ Non-target mammals ${ }^{a}$} & \multicolumn{3}{|c|}{ Wild pigs } \\
\hline & $\beta$ & LCL & UCL & $\beta$ & LCL & UCL & $\beta$ & LCL & UCL & $\beta$ & LCL & UCL \\
\hline \multicolumn{13}{|l|}{ Phase of day ${ }^{b}$} \\
\hline Day & $-0.10^{*}$ & -0.19 & -0.01 & $0.87^{*}$ & 0.63 & 1.12 & $-4.35^{*}$ & -6.37 & -2.32 & $0.55^{*}$ & 0.40 & 0.69 \\
\hline Dusk & $-0.66^{*}$ & -0.79 & -0.52 & $-1.23^{*}$ & -1.65 & -0.81 & -0.19 & -0.91 & 0.52 & $1.57^{*}$ & 1.42 & 1.71 \\
\hline Night & $-6.84^{*}$ & -7.50 & -6.18 & $-6.47^{*}$ & -8.44 & -4.50 & $1.77^{*}$ & 1.29 & 2.29 & $0.85^{*}$ & 0.72 & 0.98 \\
\hline \multicolumn{13}{|l|}{ Stage of bait station ${ }^{c}$} \\
\hline Lid open & $-0.44^{*}$ & -0.56 & -0.32 & $-0.77^{*}$ & -1.09 & -0.46 & $0.70^{*}$ & 0.30 & 1.09 & $0.09^{*}$ & 0.005 & 0.18 \\
\hline Lid closed & $-0.44^{*}$ & -0.64 & -0.24 & $-0.35^{*}$ & -0.82 & -0.12 & $1.40^{*}$ & 0.74 & 2.07 & $0.29^{*}$ & 0.15 & 0.42 \\
\hline Days since initiation & $0.09^{*}$ & 0.01 & 0.18 & 0.07 & -0.14 & 0.28 & $-0.29^{*}$ & -0.56 & -0.01 & $-0.13^{*}$ & -0.19 & -0.07 \\
\hline Hours since wild pig visitation & 0.003 & -0.04 & 0.04 & -0.01 & -0.11 & 0.09 & $-0.41^{*}$ & -0.71 & -0.12 & $-4.34^{*}$ & -4.52 & -4.15 \\
\hline
\end{tabular}

a Primarily raccoons, because white-tailed deer ceased visitation after the bait stations were deployed.

${ }^{\mathrm{b}}$ Dawn was considered as the reference phase of day.

${ }^{\mathrm{c}}$ Bait on ground (i.e., no bait station present) was considered as the reference stage of bait station.

* Indicates a statistically and biologically significant influence on the count of animals observed at bait sites.

closed), however, visits declined the longer that bait sites were operated as wild pigs were killed by the toxic bait. Visits by wild pigs were temporally clustered, meaning the hourly rate of visitation was greater sooner after the last feeding bout occurred, and declined the longer that wild pigs were away from the bait site.

For the landscape analysis, the reduced model for passerine birds held 0.83 of the model set weight, (Table S1, available online in Supporting Information). This model indicated that visitation was greater in areas with less agriculture $(\beta=-0.08 ; 95 \% \mathrm{CI}=-0.12-0.03)$ and less forest within $1,000 \mathrm{~m}(\beta=-0.26 ; 95 \% \mathrm{CI}=-0.39-0.11)$, and in areas with more intermixed landscapes within $100 \mathrm{~m}$ $(\beta=-0.03 ; 95 \% \mathrm{CI}=-0.05-0.007$; Fig. 4$)$. The reduced model for terrestrial non-targets (holding 0.60 of the model set weight) included the proportion of agriculture, rangeland, and forest within $500 \mathrm{~m}$ (Table S2, available online in Supporting Information). Visitation by terrestrial non-target species was greater in areas with more forest within $500 \mathrm{~m}(\beta=0.22 ; 95 \% \mathrm{CI}=0.01-0.49)$. The proportion of agriculture $(\beta=0.04 ; 95 \% \mathrm{CI}=-0.02-0.12)$ and rangeland $(\beta=-0.02 ; 95 \% \mathrm{CI}=-0.07-0.01)$ within $500 \mathrm{~m}$ did not influence visitation by terrestrial non-target species. Finally, the reduced model for wild pigs, holding
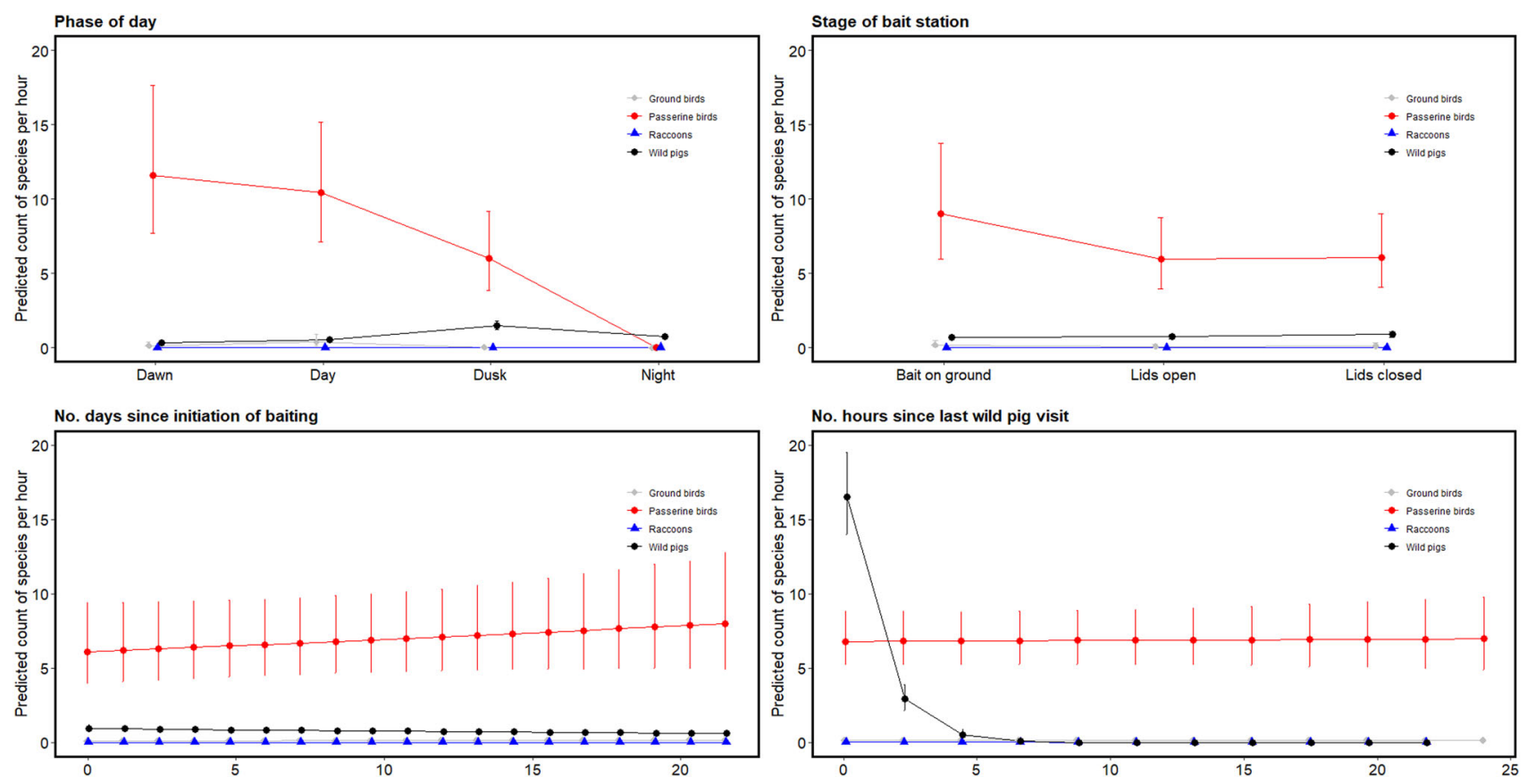

Figure 3. Predicted hourly visitation of passerine birds, ground birds, raccoons, and wild pigs relative to daily predictors at bait sites for wild pigs in north-central Texas, USA, January-March 2018. 

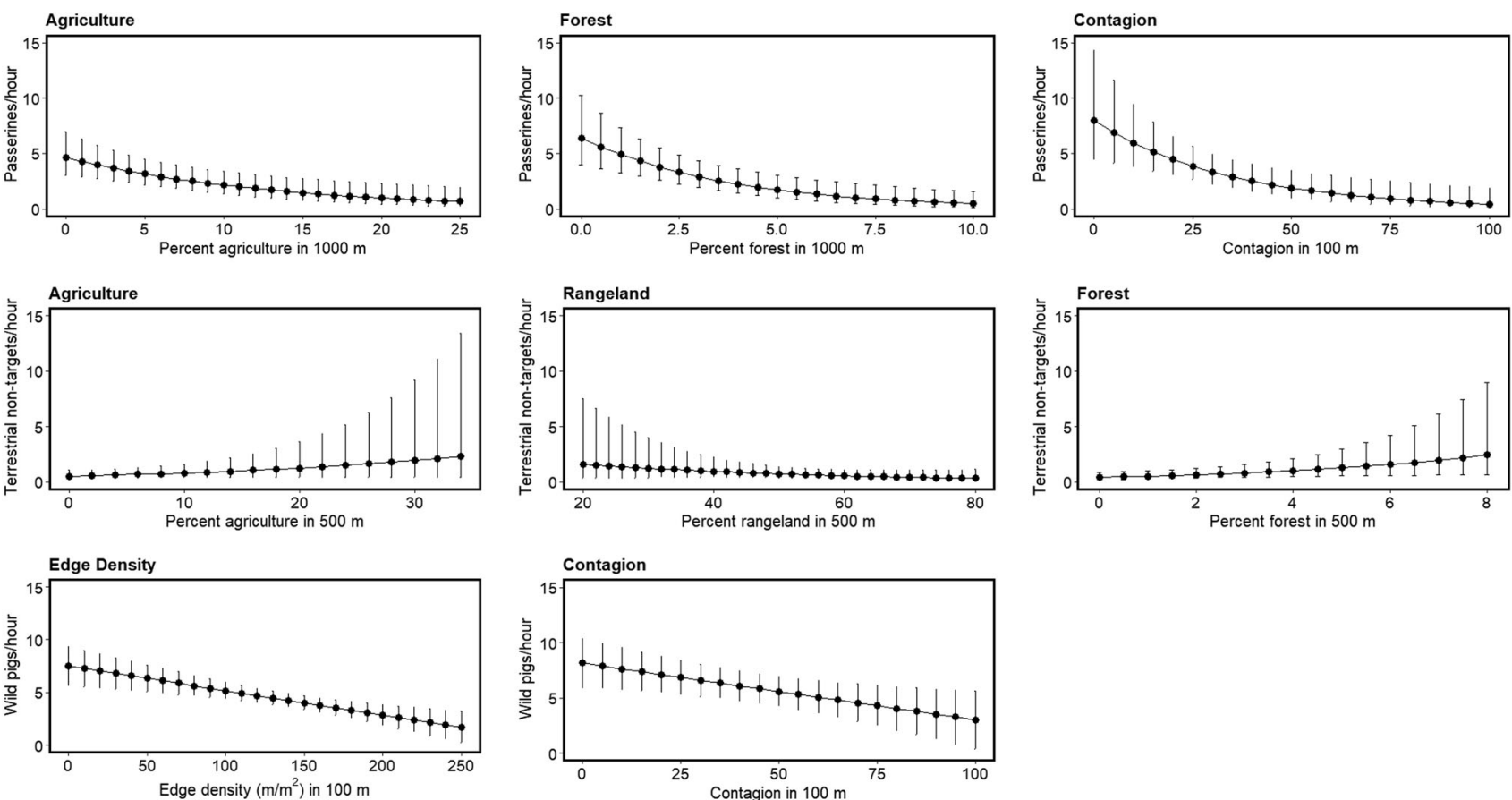

Figure 4. Predicted hourly visitation (and $95 \% \mathrm{CIs}$ ) of passerine birds, terrestrial non-target species (i.e., combination of ground birds, raccoons, and whitetailed deer), and wild pigs relative to the most important landscape predictors identified at bait sites for wild pigs in north-central Texas, USA, January-March 2018.

0.88 of the model set weight, included metrics of edge density and contagion within $100 \mathrm{~m}$ (Table S3, available online in Supporting Information). Visitation by wild pigs was greatest in areas with lower edge density $(\beta=-3.33$; 95\% $\mathrm{CI}=-5.21--1.44)$, but with more intermixed landscapes $\quad(\beta=-7.39 ; \quad 95 \% \quad C I=-13.54--1.24)$ within $100 \mathrm{~m}$.
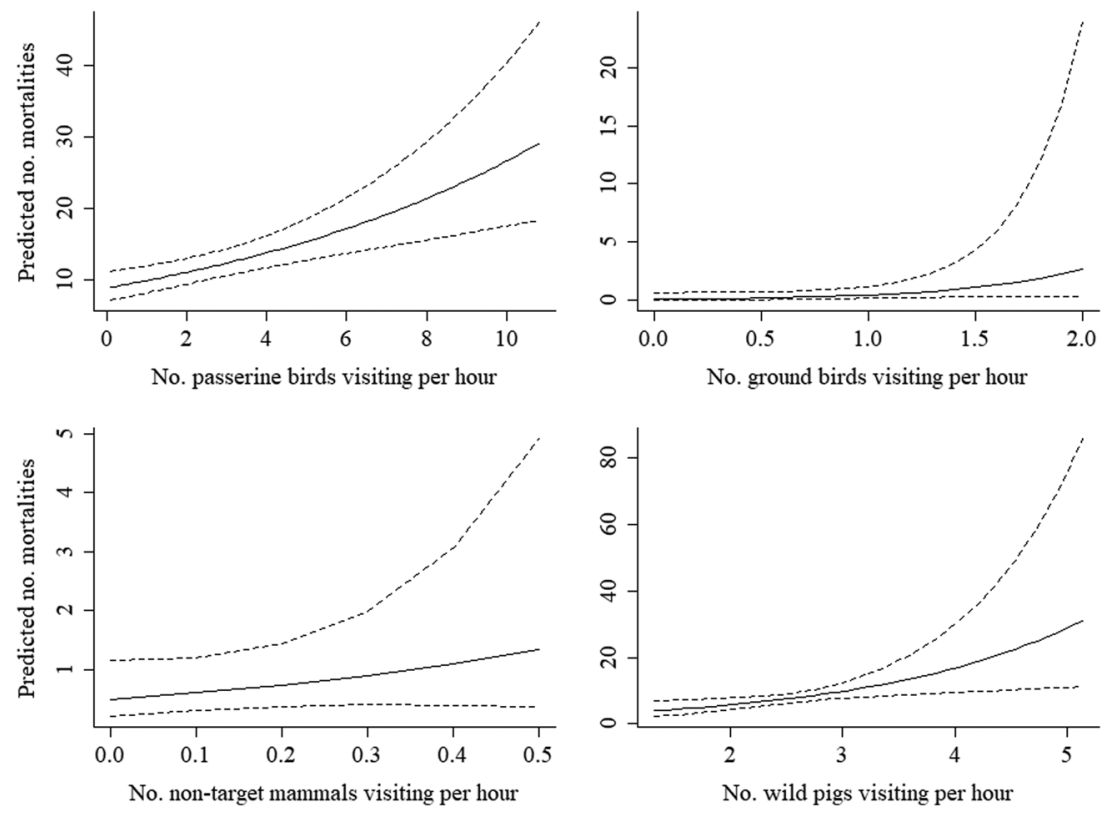

Figure 5. Predicted number of mortalities (and 95\% CIs) based from a deployment of sodium nitrite toxic bait for wild pigs relative to their respective rates of visitation at bait sites in north-central Texas, USA, January-March 2018. 
sites with greater visitation by wild pigs $(\beta=0.54 ; 95 \%$ $\mathrm{CI}=0.16-0.96$ ).

\section{DISCUSSION}

Results from our post hoc analysis indicate some potential strategies that could be used for minimizing visitations by non-target species and reducing the hazards from HOGGONE. However, our results also make it clear that there is no single strategy to eliminate visitations by all non-target species, which has also been demonstrated in other studies (Campbell and Long 2007, 2008; Snow et al. 2016). Passerine birds experienced the greatest hazards from HOGGONE in the 2018 trial (United States Department of Agriculture 2018), and our results show that those hazards increased as more passerine birds were present at bait sites. The hazards for passerine birds observed in our study during winter-early spring were especially apparent because large flocks of birds utilized bait sites together, and many birds were exposed to small amounts of bait dropped outside of the bait station by wild pigs. To reduce those hazards, we demonstrated the importance of reducing visitation by passerine birds. Daily strategies for minimizing passerine birds at bait sites is to offer bait at night, deploy bait stations as early as possible in the prebaiting process, and to reduce the duration of prebaiting as much as possible. These strategies will limit the amount of food available that may attract passerine birds. Deploying bait only at night may seem onerous, but use of common technology could assist (e.g., timers on feeders during the prebaiting periods). Additionally, once wild pigs are sufficiently accustomed to using the bait stations, toxic HOGGONE only needs to be deployed during one night, making the nighttime work infrequent.

Our results also show it may be important to place bait sites away from areas where passerine birds exist in greatest numbers. Landscapes with the greatest diversity and abundance of grassland birds in rangeland ecosystems are landscapes with greater heterogeneity of land cover types (Hovick et al. 2014). This aligns with where we observed the greatest use of bait sites by passerine birds. To reduce this, our results suggest placing bait sites in more homogeneous landscapes with either more agriculture or forest (within 1,000 m), and avoid sites with more localized heterogeneity of land cover types (within $100 \mathrm{~m}$ ). Our data showed that utilizing these features of the landscape seemed to reduce passerine bird visitations.

We made two important observations about passerine birds at bait sites that are worthy of discussing. First, we observed the common behavior of small granivorous birds (e.g., Best 1986, Diaz 1990, Perkins et al. 2007) being attracted to small particles of whole-kernel corn (i.e, broken up kernels and flecks of corn) that persisted in the soil days after no new whole-kernel corn was placed on the ground. These particles were residue from the initial 2-6 days of prebaiting where whole-kernel corn was placed directly on the ground to locate wild pigs. The bait stations were placed directly on top of the residue and may have created a continual attraction for passerine birds throughout the study. This attraction ultimately facilitated birds finding the spilled toxic HOGGONE (also containing small particles of grains) once the toxic bait was offered. Secondly, we observed that the soil around the bait sites became void of vegetation and was greatly disturbed following multiple days of wild pig visitation. This disturbance is similar to shallowdepth tilling (i.e., non-inversion tilling), which may increase invertebrate and seed availability for passerine birds (Cunningham et al. 2004, Cunningham et al. 2005) and attract them to the area. An important line of research stemming from these observations will be to place bait stations away from the residues from prebaiting, or the patches of disturbed soil, and assess whether visits by passerine birds are reduced.

Visitations by ground birds and non-target mammals were infrequent compared to passerine birds, and the frequency of ground birds and non-target mammals did not seem to influence their likelihood of hazards. Most ground birds visited during the day and raccoons visited during the night, matching their periods of peak feeding activity during winter (Sharp and Sharp 1956, Porter et al. 1980). Although forest land cover only comprised $<1 \%$ of the landscape in our rangeland study area, it played an important role in influencing these non-target species. Landscapes with fewer parcels of forest (within $500 \mathrm{~m}$ ) seemed to minimize visitations by some terrestrial non-target species (i.e., raccoons, wild turkey, bobwhite quail), which agrees with the habitat suitability requirements for those species (e.g., Roseberry and Sudkamp 1998, Glennon and Porter 1999, Broadfoot et al. 2001).

Finally, toxic HOGGONE was more effective as more wild pigs visited bait sites. To maximize visitations to bait sites by wild pigs we found that deploying bait so it was available at dusk and night was efficient for attracting wild pigs, and had the added benefit of not attracting birds. Other researchers have recommended nocturnal deployment of baits for wild pigs to improve target specificity (O’Brien 1986, Lapidge et al. 2004, Bengsen et al. 2008), and one study confirmed this approach reduced non-target consumption of baits in the tropical rainforest of Queensland, Australia (Bengsen et al. 2011). The safest method for reducing exposure to most non-target species would be a nocturnal strategy deploying toxic bait only at night followed by removing any toxic bait spilled outside of the bait stations by wild pigs, or employing a bird deterrent device (i.e., frightening device) at dawn. In addition, wild pigs seemed to temporally cluster their feedings, because they visited at a greater rate sooner after the last feeding bout occurred. Also, this may indicate that wild pigs attract more wild pigs. This is not surprising considering wild pigs are social animals, and oestrous sows have been used to attract wild pigs into traps in other studies (e.g., Choquenot et al. 1993, McIlroy and Gifford 2005). Finally, the landscape analysis revealed that bait sites with lower edge density but greater intermixing of cover-types (within $100 \mathrm{~m}$ ) had the greatest visitation by wild pigs. These attributes suggest that areas with straight versus tortuous edges, and 
bisecting 2 or more land covers have greater visitation by wild pigs (e.g., linear features of the landscape, such as edges of agricultural fields or riparian corridors).

Some limits of this study exist. Primarily, this was a post hoc analysis which can lead to spurious results (Anderson et al. 2001), but we attempted to negate this by careful selection of a limited number of meaningful predictor variables (Anderson and Burnham 2002). Secondly, this study was conducted near the geographic center of the invaded range of wild pigs in the US (McClure et al. 2015, Corn and Jordan 2017, Snow et al. 2017b) in the state with the largest population of wild pigs (estimated at 2.5 million animals; Lewis et al. 2019), and therefore a likely area for toxic bait to be used to control wild pigs. However, implications from this study are restricted to rangelands and more investigation is needed in other ecosystems. For instance, a 2019 evaluation of HOGGONE in forested wetlands of southern Alabama, USA, revealed no hazards for birds (N. P. Snow, unpublished data), likely because fewer small, granivorous birds inhabited that landscape. Finally, this study was conducted during the late winter in attempt to bait wild pigs while their food resources were most scarce. However, an unintentional consequence of this was the passage of some migratory birds, such as white-crowned sparrows, moving north (Mills 2005), which may have exacerbated the density of passerine birds at the toxic bait sites, particularly when toxic HOGGONE was deployed (early March).

\section{MANAGEMENT IMPLICATIONS}

There is no single strategy that will completely eliminate visitations by all non-target species to toxic HOGGONE bait sites for wild pigs in rangelands. However, we found evidence that selecting bait sites in less preferred areas for passerine birds (i.e., more homogeneous land cover), offering bait at night in wild pig-specific bait stations, and removing spilled bait as quickly as possible, perhaps coupled with employing a bird frightening device the morning after toxic baiting, appear to be potential strategies for minimizing hazards for the most vulnerable guild of non-target species. We also recommend not placing bait stations directly at sites where residual particles of grain (from prebaiting) are available on the ground. Finally, we found evidence that allowing time for wild pigs to attract others to the bait sites, and baiting along linear features of the landscape (e.g., agricultural edges or riparian corridors), may increase visitation by that species.

\section{ACKNOWLEDGMENTS}

The research was supported by the United States Department of Agriculture. The findings and conclusions in this publication are those of the authors and should not be construed to represent any official U.S. Government determination or policy. We thank J. Davis and G. Studdard for permission and logistical support at the study site. We thank C. Ellis, J. Foster, B. Friesenhahn, C. Kohler, I. Messer, P. Ward, C. Wickham, and A. Zarvoi for assisting with data collection. We also thank M. Smith (Associate
Editor), A. Knipps (Editorial Assistant), and 2 anonymous reviewers for their comments on this manuscript. Mention of commercial products or companies does not represent an endorsement by the US government.

\section{LITERATURE CITED}

Anderson, D. R., and K. P. Burnham. 2002. Avoiding pitfalls when using information-theoretic methods. Journal of Wildlife Management 66:912-918.

Anderson, D. R., K. P. Burnham, W. R. Gould, and S. Cherry. 2001. Concerns about finding effects that are actually spurious. Wildlife Society Bulletin 29:311-316.

Aschim, R. A., and R. K. Brook. 2019. Evaluating cost-effective methods for rapid and repeatable national scale detection and mapping of invasive species spread. Scientific Reports 9:7254.

Bailey, R. G. 1980. Description of the ecoregions of the United States. US Department of Agriculture, Forest Service.

Barrios-Garcia, M. N., and S. A. Ballari. 2012. Impact of wild boar (Sus scrofa) in its introduced and native range: a review. Biological Invasions 14:2283-2300.

Barton, K. 2009. MuMIn: multi-model inference, R package version 0.12. 0. <http://r-forge.r-project.org/projects/mumin/>. Accessed 22 Jan 2021.

Bengsen, A. J., M. N. Gentle, J. L. Mitchell, H. E. Pearson, and G. R. Saunders. 2014. Impacts and management of wild pigs Sus scrofa in Australia. Mammal Review 44:135-147.

Bengsen, A., L. K. P. Leung, S. J. Lapidge, and I. J. Gordon. 2008. The development of target-specific vertebrate pest management tools for complex faunal communities. Ecological Management \& Restoration 9:209-216.

Bengsen, A. J., L. K.-P. Leung, S. J. Lapidge, and I. J. Gordon. 2011. Target-specificity of feral pig baits under different conditions in a tropical rainforest. Wildlife Research 38:370-379.

Best, L. B. 1986. Conservation tillage: ecological traps for nesting birds? Wildlife Society Bulletin (1973-2006) 14:308-317.

Bevins, S. N., K. Pedersen, M. W. Lutman, T. Gidlewski, and T. J. Deliberto. 2014. Consequences associated with the recent range expansion of nonnative feral swine. BioScience 64:291-299.

Broadfoot, J. D., R. C. Rosatte, and D. T. O'Leary. 2001. Raccoon and skunk population models for urban disease control planning in Ontario, Canada. Ecological Applications 11:295-303.

Brook, R. K., and F. M. van Beest. 2014. Feral wild boar distribution and perceptions of risk on the central Canadian prairies. Wildlife Society Bulletin 38:486-494.

Brooks, M. E., K. Kristensen, K. J. van Benthem, A. Magnusson, C. W. Berg, A. Nielsen, H. J. Skaug, M. Maechler, B. M. Bolker. 2017. glmmTMB Balances Speed and Flexibility Among Packages for Zero-inflated Generalized Linear Mixed Modeling. The R Journal 9(2):378-400.

Burnham, K. P., and D. R. Anderson. 2002. Model selection and multimodel inference: a practical information-theoretic approach. second edition. Springer Science \& Business Media, New York, NY, USA.

Campbell, T. A., J. A. Foster, M. J. Bodenchuk, J. D. Eisemann, L. Staples, and S. J. Lapidge. 2013. Effectiveness and target-specificity of a novel design of food dispenser to deliver a toxin to feral swine in the United States. International Journal of Pest Management 59:197-204.

Campbell, T. A., and D. B. Long. 2007. Species-specific visitation and removal of baits for delivery of pharmaceuticals to feral swine. Journal of Wildlife Diseases 43:485-491.

Campbell, T. A., and D. B. Long. 2008. Mammalian visitation to candidate feral swine attractants. Journal of Wildlife Management 72:305-309.

Campbell, T. A., and D. B. Long. 2009. Feral swine damage and damage management in forested ecosystems. Forest Ecology and Management 257:2319-2326.

Campbell, T. A., D. B. Long, and G. Massei. 2011. Efficacy of the BoarOperated-System to deliver baits to feral swine. Preventive Veterinary Medicine 98:243-249.

Choquenot, D., R. J. Kilgour, and B. S. Lukins. 1993. An evaluation of feral pig trapping. Wildlife Research 20:15-21.

Corn, J. L., and T. R. Jordan. 2017. Development of the national feral swine map, 1982-2016. Wildlife Society Bulletin 41:758-763. 
Cunningham, H. M., R. B. Bradbury, K. Chaney, and A. Wilcox. 2005 Effect of non-inversion tillage on field usage by UK farmland birds in winter. Bird Study 52:173-179.

Cunningham, H. M., K. Chaney, R. B. Bradbury, and A. Wilcox. 2004. Non-inversion tillage and farmland birds: a review with special reference to the UK and Europe. Ibis 146:192-202.

Danks, Z. D., and W. F. Porter. 2010. Temporal, spatial, and landscape habitat characteristics of moose-vehicle collisions in western Maine. Journal of Wildlife Management 74:1229-1241.

DeGroot, S. L. 2018. Factors predicting acceptability of toxicant usage to control feral swine. M.S. Thesis, Colorado State University, Fort Collins, USA.

Diaz, M. 1990. Interspecific patterns of seed selection among granivorous passerines: effects of seed size, seed nutritive value and bird morphology. Ibis 132:467-476.

Ferretti, F., J. Coats, D. P. Cowan, S. Pietravalle, and G. Massei. 2018. Seasonal variation in effectiveness of the boar-operated system to deliver baits to wild boar. Pest Management Science 74:422-429.

Fletcher, W., T. Creekmore, M. Smith, and V. Nettles. 1990. A field trial to determine the feasibility of delivering oral vaccines to wild swine. Journal of Wildlife Diseases 26:502-510.

Glennon, M. J., and W. F. Porter. 1999. Using satellite imagery to assess landscape-scale habitat for wild turkeys. Wildlife Society Bulletin 27:646-653.

Hovick, T. J., R. D. Elmore, and S. D. Fuhlendorf. 2014. Structural heterogeneity increases diversity of non-breeding grassland birds. Ecosphere 5:1-13.

Howald, G., C. J. Donlan, J. P. Galvan, J. C. Russell, J. Parkes, A. Samaniego, Y. Wang, D. Veitch, P. Genovesi, M. Pascal, A. Saunders, and B. Tershy. 2007. Invasive rodent eradication on islands. Conservation Biology 21:1258-1268.

Ivan, J. S., and E. S. Newkirk. 2016. CPW Photo Warehouse: a custom database to facilitate archiving, identifying, summarizing and managing photo data collected from camera traps. Methods in Ecology and Evolution 7:499-504.

Jin, S., L. Yang, P. Danielson, C. Homer, J. Fry, and G. Xian. 2013. A comprehensive change detection method for updating the National Land Cover Database to circa 2011. Remote Sensing of Environment 132:159-175.

Kay, S. L., J. W. Fischer, A. J. Monaghan, J. C. Beasley, R. Boughton, T. A. Campbell, S. M. Cooper, S. S. Ditchkoff, S. B. Hartley, J. C. Kilgo, S. M. Wisely, A. C. Wyckoff, K. C. VerCauteren, and K. M. Pepin. 2017. Quantifying drivers of wild pig movement across multiple spatial and temporal scales. Movement ecology 5:14.

Keiter, D. A., J. J. Mayer, and J. C. Beasley. 2016. What is in a "common" name? A call for consistent terminology for nonnative Sus scrofa. Wildlife Society Bulletin 40:384-387.

Koichi, K., A. Cottrell, K. K. Sangha, and I. J. Gordon. 2013. What determines the acceptability of wildlife control methods? A case of feral pig management in the Wet Tropics World Heritage Area, Australia. Human Dimensions of Wildlife 18:97-108.

Lapidge, S. J., B. Cowled, and M. Smith. 2004. Ecology, genetics and socio-biology: practical tools in the design of target-specific feral pig baits and baiting procedures. Pages 317-322 in R. M. Timm and W. P. Gorenzel, editors. Proceedings of the 21st Vertebrate Pest Conference. University of California, Davis.

Lapidge, S., J. Wishart, L. Staples, K. Fagerstone, T. Campbell, and J. Eisemann. 2012. Development of a feral swine toxic bait (Hog-Gone $\left.{ }^{\circledR}\right)$ and bait hopper (Hog-Hopper ${ }^{\mathrm{TM}}$ ) in Australia and the USA. Pages 19-24 in S. N. Frey, editor. Proceedings of the 14th Wildlife Damage Management Conference, Nebraska City, Nebraska.

Lavelle, M. J., N. P. Snow, J. W. Fischer, J. M. Halseth, E. H. VanNatta, and K. C. VerCauteren. 2017. Attractants for wild pigs: current use, availability, needs, and future potential. European Journal of Wildlife Research 63:86.

Lavelle, M. J., N. P. Snow, J. M. Halseth, J. C. Kinsey, J. A. Foster, and K. C. VerCauteren. 2018a. Development and evaluation of a bait station for selectively dispensing bait to invasive wild pigs. Wildlife Society Bulletin 42:102-110.

Lavelle, M. J., N. P. Snow, J. M. Halseth, E. H. VanNatta, H. N. Sanders, and K. C. VerCauteren. 2018b. Evaluation of movement behaviors to inform toxic baiting strategies for invasive wild pigs (Sus scrofa). Pest Management Science 74:2504-2510.
Lewis, J. S., J. L. Corn, J. J. Mayer, T. R. Jordan, M. L. Farnsworth, C. L. Burdett, K. C. VerCauteren, S. J. Sweeney, and R. S. Miller. 2019. Historical, current, and potential population size estimates of invasive wild pigs (Sus scrofa) in the United States. Biological Invasions 21:2373-2384.

Lewis, J. S., M. L. Farnsworth, C. L. Burdett, D. M. Theobald, M. Gray, and R. S. Miller. 2017. Biotic and abiotic factors predicting the global distribution and population density of an invasive large mammal. Scientific Reports 7:44152.

Li, H., and J. F. Reynolds. 1993. A new contagion index to quantify spatial patterns of landscapes. Landscape ecology 8:155-162.

Long, D. B., T. A. Campbell, and G. Massei. 2010. Evaluation of feral swine-specific feeder systems. Rangelands 32:8-13.

Massei, G., J. Coats, R. Quy, K. Storer, and D. P. Cowan. 2010. The Boar-Operated-System: a novel method to deliver baits to wild pigs. Journal of Wildlife Management 74:333-336.

Mayer, J., and I. L. Brisbin, editors. 2009. Wild pigs: biology, damage, control techniques and management. Savannah River National Laboratory Report Report SRNL-RP-2009-00869, Aiken, South Carolina, USA.

McClure, M. L., C. L. Burdett, M. L. Farnsworth, M. W. Lutman, D. M. Theobald, P. D. Riggs, D. A. Grear, and R. S. Miller. 2015. Modeling and mapping the probability of occurrence of invasive wild pigs across the contiguous United States. PloS One 10:e0133771.

McClure, M. L., C. L. Burdett, M. L. Farnsworth, S. J. Sweeney, and R. S. Miller. 2018. A globally-distributed alien invasive species poses risks to United States imperiled species. Scientific Reports 8:5331.

McIlroy, J., and E. Gifford. 2005. Are oestrous feral pigs, Sus scrofa, useful as trapping lures? Wildlife Research 32:605-608.

Mills, A. M. 2005. Changes in the timing of spring and autumn migration in North American migrant passerines during a period of global warming. Ibis 147:259-269.

O'Brien, P. H. 1986. An approach to the design of target-specific vertebrate pest control systems. Pages 247-252 in T. P. Salmon, editor. Proceedings of the 12th Vertebrate Pest Conference. University of California, Davis.

Perkins, A. J., G. Anderson, and J. D. Wilson. 2007. Seed food preferences of granivorous farmland passerines. Bird Study 54:46-53.

Pimentel, D., R. Zuniga, and D. Morrison. 2005. Update on the environmental and economic costs associated with alien-invasive species in the United States. Ecological Economics 52:273-288.

Poché, R. M., D. Poché, G. Franckowiak, D. J. Somers, L. N. Briley, B. Tseveenjav, and L. Polyakova. 2018. Field evaluation of low-dose warfarin baits to control wild pigs (Sus scrofa) in North Texas. PloS One 13:e0206070.

Porter, W. F., R. D. Tangen, G. C. Nelson, and D. A. Hamilton. 1980. Effects of corn food plots on wild turkeys in the upper Mississippi Valley. Journal of Wildlife Management 456-462.

R Core Team. 2020. R: a language and environment for statistical computing. R Foundation for Statistical Computing, Vienna, Austria. https://www.R-project.org/

Roseberry, J. L., and S. D. Sudkamp. 1998. Assessing the suitability of landscapes for northern bobwhite. Journal of Wildlife Management 62:895-902.

Seward, N. W., K. C. VerCauteren, G. W. Witmer, and R. M. Engeman. 2004. Feral swine impacts on agriculture and the environment. Sheep \& Goat Research Journal 19:34-40.

Shapiro, L., C. Eason, C. Bunt, S. Hix, P. Aylett, and D. MacMorran. 2016. Efficacy of encapsulated sodium nitrite as a new tool for feral pig management. Journal of Pest Science 89:489-495.

Sharp, W. M., and L. H. Sharp. 1956. Nocturnal movements and behavior of wild raccoons at a winter feeding station. Journal of Mammalogy $37: 170-177$

Snow, N. P., J. A. Foster, J. C. Kinsey, S. T. Humphrys, L. D. Staples, D. G. Hewitt, and K. C. VerCauteren. 2017a. Development of toxic bait to control invasive wild pigs and reduce damage. Wildlife Society Bulletin 41:256-263.

Snow, N. P., J. A. Foster, E. H. VanNatta, K. E. Horak, S. T. Humphrys, L. D. Staples, D. G. Hewitt, and K. C. VerCauteren. 2018. Potential secondary poisoning risks to non-targets from a sodium nitrite toxic bait for invasive wild pigs. Pest Management Science 74:181-188.

Snow, N. P., J. M. Halseth, M. J. Lavelle, T. E. Hanson, C. R. Blass, J. A. Foster, S. T. Humphrys, L. D. Staples, D. G. Hewitt, and K. C. 
VerCauteren. 2016. Bait preference of free-ranging feral swine for delivery of a novel toxicant. PLoS One 11:e0146712.

Snow, N. P., M. A. Jarzyna, and K. C. VerCauteren. 2017b. Interpreting and predicting the spread of invasive wild pigs. Journal of Applied Ecology 54:2022-2032.

Snow, N. P., M. J. Lavelle, J. M. Halseth, C. R. Blass, J. A. Foster, and K. C. Vercauteren. 2017c. Strength testing of raccoons and invasive wild pigs for a species-specific bait station. Wildlife Society Bulletin 41:264-270.

Snow, N. P., M. J. Lavelle, J. M. Halseth, C. R. Blass, J. A. Foster, and K. C. VerCauteren. 2017d. Strength testing of raccoons and invasive wild pigs for a species-specific bait station. Wildlife Society Bulletin 41:264-270

Snow, N. P., M. J. Lavelle, J. M. Halseth, M. P. Glow, E. H. VanNatta, A. J. Davis, K. M. Pepin, R. T. Tabor, B. R. Leland, L. D. Staples, and K. C. VerCauteren. 2019. Exposure of a population of invasive wild pigs to simulated toxic bait containing biomarker: implications for population reduction. Pest Management Science 75:1140-1149.

Snow, N. P., and K. C. VerCauteren. 2019. Movement responses inform effectiveness and consequences of baiting wild pigs for population control. Crop Protection 124:104835.
Sweetapple, P., G. Nugent, and W. Fraser. 2002. Long-term changes in rat abundance following possum control. He Korero Paihama: Possum Research News 17:1-2.

Tabak, M. A., A. J. Piaggio, R. S. Miller, R. A. Sweitzer, and H. B. Ernest. 2017. Anthropogenic factors predict movement of an invasive species. Ecosphere 8:e01844.

TuckerWilliams, E. 2018. Stakeholder Perspectives on Wild Pig Management in Alabama. M.S. Thesis, Auburn University, Alabama, USA.

United States Department of Agriculture. 2018. APHIS Wildlife Services conducts first field trial of feral swine toxic bait; plans modifications to mitigate hazards to non-target species. <https://www.aphis.usda.gov/ aphis/newsroom/stakeholder-info/SA_By_Date/SA-2018/SA-06/feralswine-bait-trial>. Accessed 29 Jul 2019.

\section{SUPPORTING INFORMATION}

Additional supporting information may be found in the online version of this article at the publisher's website. 